\title{
Review
}

\section{Implantable Cardioverter Defibrillators for Prevention of Sudden Cardiac Death}

\author{
Rishi SuKhiJa, M.D., Vimal Mehta, M.D., * Marino LeOnardi, M.D., JaWAHAR L. MehTA, M.D., PH.D. \\ Department of Internal Medicine, Division of Cardiovascular Medicine, University of Arkansas for Medical Sciences, Little Rock, \\ Arkansas, USA, and *Division of Cardiology, GB Pant Hospital, New Delhi, India
}

\begin{abstract}
Summary: Despite the multiple advances in the field of cardiovascular medicine, the incidence of sudden cardiac death (SCD) continues to rise. Of all SCDs, $<25 \%$ occur in individuals deemed at high risk by current risk-stratification algorithms; hence, these risk-stratification algorithms are not satisfactory. Until better markers are identified to risk stratify patients, we will see an increasing use of implantable cardioverter defibrillators (ICDs). However, even with the increase in defibrillator use, the impact on overall incidence of SCD may only be modest, as many individuals experience $\mathrm{SCD}$ as the first manifestation of cardiovascular disease. Another important challenge is widespread availability of automated external defibrillators and effective utilization of public access defibrillation programs for timely and appropriate management of out-of-hospital victims with cardiac arrest. This review discusses the current understanding on SCD, risk stratification, and management aimed at reducing $S C D$, particularly with the use of ICDs.
\end{abstract}

Key words: coronary artery disease, congestive heart failure, implantable cardioverter defibrillators, left ventricular ejection fraction, sudden cardiac death

Clin. Cardiol. 2007; 30: 3-8, @ 2007 Wiley Periodicals, Inc.

\section{Introduction}

Sudden cardiac death (SCD), defined as unexpected death from a cardiac cause occurring within a short time, generally

\section{Address for reprints:}

J.L. Mehta, M.D., Ph.D.

Division of Cardiovascular Medicine

University of Arkansas for Medical Sciences

Mail Slot 532, 4301 West Markham St.

Little Rock, AR 72205-7199, USA

e-mail: mehtajl@uams.edu

Received: January 24, 2006

Accepted with revision: May 9, 2006

Published online in Wiley InterScience

(www.interscience.wiley.com).

DOI:10.1002/clc.20001

(C) 2007 Wiley Periodicals, Inc. within $1 \mathrm{~h}$ of symptom onset, is a common cause of death throughout the world, with more than 3 million persons dying yearly from SCD ${ }^{1,2}$ In USA alone, approximately 1,000 persons experience SCD every day, with SCD occurring almost every $1 \frac{1}{2} \mathrm{~min} .{ }^{3}$ Sudden cardiac death has a bimodal incidence peaking between birth and 6 months of age (sudden infant death syndrome) and between 45 and 75 years of age (due to development of coronary artery disease [CAD] $).{ }^{1}$

Sudden cardiac death is the first presentation in about onethird of patients with CAD. Coronary artery disease, with or without myocardial infarction (MI), is responsible for approximately $75-80 \%$ of all SCDs ${ }^{1}$ and is three times more common in men than in women. Cardiomyopathies (dilated and hypertrophic) and primary electrical abnormalities (long and short QT syndromes, and Brugada syndrome) account for most of the remainder. Acute MI is evident in only about $20 \%$ of the cases of SCD, contrary to the general misconception that SCD is a result of MI. As most cases of SCD are a result of electrical instability, SCD can be best labeled as a "major electrical accident." 1,2

In persons at high risk for CAD, the risk of SCD is two to four times higher than that in the general population, which increases to four to six times if they have established CAD and increases further to six to nine times if they develop congestive heart failure (CHF). ${ }^{4}$

\section{Pathophysiology of Sudden Cardiac Death}

The pathophysiology of SCD involves interaction of triggering events and an abnormal substrate that induces electrical instability. Most commonly, SCD is caused by rapid ventricular tachycardia (VT) and ventricular fibrillation (VF) ${ }^{5}$ Occurrence of frequent ventricular premature complexes (VPCs) $(\geq 10 \mathrm{VPCs} / \mathrm{h}$ ) and even nonsustained VT (NSVT) in the absence of structural heart disease is often benign. Even in the presence of structural heart disease, VPCs or NSVT are poor predictors of SCD.

Whereas ventricular tachyarrhythmias are responsible for a vast majority ( 85\%) of cases of $\mathrm{SCD},{ }^{5}$ bradyarrhythmias culminating into asystole, often with electrical-mechanical dissociation, are usually the result of end-stage CHF and are associated with grave prognosis. ${ }^{1,2}$ Hence, prevention of SCD should target prevention of ventricular arrhythmias. 


\section{Risk Stratification}

The most important risk factor with highest predictive value for SCD are left ventricular dysfunction with ejection fraction $(\mathrm{LVEF}) \leq 40 \%{ }^{2}$ The risk of mortality in relation to LVEF is nonlinear, with a marked increase when LVEF falls $<40 \%$. With increasing New York Heart Association (NYHA) heart failure class the total mortality increases, but paradoxically the percentage of patients who die suddenly decreases and pump failure deaths increase. Thus, over one-half of NYHA class II patients with CHF die suddenly, whereas only $10-40 \%$ of patients in NYHA class IV suffer SCD. ${ }^{6}$

Various electrocardiographic ${ }^{7}$ and autonomic markers ${ }^{8}$ have been examined for assessing the risk of ventricular arrhythmias; however, their importance in risk stratification is debatable and their positive predictive value, when considered either alone or in combination, is low. Nonetheless, the negative predictive value of signal-averaged electrocardiograms (ECG) and microvolt T-wave alternans (m-TWA) in patients post $\mathrm{MI}^{9}$ is high. Taken together, they might identify patients at arrhythmic risk in the intermediate- to low-risk group and those who are not likely to benefit from an implantable cardioveter defibrillator (ICD).

An electrophysiologic (EP) study with programmed electrical stimulation is a useful test for risk stratification by way of inducibility of VT and for identification of the site of origin of wide complex tachycardia, and it is one of the tests for investigating unexplained syncope. ${ }^{10}$ Table 1 lists the indications for EP study. In some patients with spontaneous sustained VT, radiofrequency catheter ablation of the arrhythmic substrate may be curative. ${ }^{10}$

\section{Prevention of Sudden Cardiac Death}

\section{Coronary Artery Disease}

Pharmacologic treatment: Early attempts at preventing SCD were directed at suppression of ventricular ectopy. It was several years before it was realized that medical treatment of asymptomatic VPCs and NSVT was not only inappropriate but also dangerous. The Cardiac Arrhythmia Suppression Trial (CAST) demonstrated that patients with CAD and modest LV dysfunction, given antiarrhythmic drugs such as flecainide or propafenone, may suffer higher mortality than controls. ${ }^{11}$ Thus it was realized that a "clean" Holter did not assure freedom from SCD, and the presence of a "chaotic" Holter with multiple VPCs did not portend a sinister outcome. During the 1980s, it also became clear that beta blockers could provide reduction of SCD, an effect not attributable solely to their anti-ischemic effects. ${ }^{12}$ The reduction of overall mortality and SCD with beta blockers is greatest in patients with LV dysfunction. In fact, of all antiarrhythmic drugs, only beta blockers ${ }^{12,13}$ and perhaps amiodarone, particularly in association with beta blockers ${ }^{14}$ reduce SCD. Recently, angiotensinconverting enzyme (ACE) inhibitors, ${ }^{15}$ angiotensin receptor blockers, ${ }^{16}$ aldosterone receptor antagonists, ${ }^{17}$ aspirin, and statins have also been demonstrated to reduce $\mathrm{SCD} .{ }^{18}$

TABLE 1 Patients who will or will not benefit from electrophysiologic study

Patients not likely to benefit

1. Mildly symptomatic or asymptomatic ventricular ectopic activity

2. Primary VT/VF in the setting of acute MI which was aborted by thrombolytic therapy or primary angioplasty, which results in normal LV function, normal stress test and no symptomatic ectopy

3. Cardiomyopathies (hypertrophic and nonischemic dilated) for risk stratification

Patients likely to benefit

Diagnosis and risk stratification

1. Unexplained syncope when other noninvasive tests have been inconclusive

2. CAD, LV dysfunction, and NSVT

3. Arrhythmogenic right ventricular dysplasia for inducibility of VT

4. Survivors of SCD or VT with hemodynamic compromise prior to ICD implantation to identify and characterize an inducible tachyarrhythmia, particularly one that may be cured with catheter ablation techniques or to rule out a supraventricular arrhythmia that might complicate management of an ICD (some authorities advocate this approach, most would directly go in for an ICD implantation)

5. Brugada syndrome (not all the studies support role of EPS in risk stratification)

Catheter ablation

1. Bundle-branch reentrant tachycardia (which is usually seen in nonischemic dilated cardiomyopathy)

2. VT like right ventricular outflow tract tachycardia, idiopathic LV tachycardia, fascicular tachycardia (in these patients catheter ablation is curative)

3. Arrhythmogenic right ventricular dysplasia for catheter ablation (although acute success rates of 60-90\% have been reported, VT recurrences are common (upto 60\%) mainly because of the progressive nature of the disease)

4. Ventricular arrhythmias resulting from myocardial scarring secondary to CAD

5. Symptomatic WPW syndrome

Abbreviations: $\mathrm{VT}=$ ventricular tachycardia, $\mathrm{VF}=$ ventricular fibrillation, $\mathrm{MI}=$ myocardial infarction, $\mathrm{LV}=$ left ventricular, $\mathrm{CAD}=$ coronary artery disease, NSVT = nonsustained ventricular tachycardia, $\mathrm{SCD}=$ sudden cardiac death, ICD = implantable cardioverter-defibrillator, EPS = electrophysiologic study. 
Revascularization: Coronary revascularization alone has been shown to prevent ischemia-induced recurrent VT/VF. $1,2,18$

\section{Defibrillators}

- Secondary Prevention Trials: Some patients who survived an episode of SCD and/or sustained VT with hemodynamic compromise were implanted with an ICD (Table 2), and their outcome was compared with similar patients on drug therapy alone in three different trials (Table 3), namely, Antiarrhythmics Versus Implantable Defibrillator trial (AVID), ${ }^{19}$ Canadian Implantable Defibrillator Study (CIDS) ${ }^{20}$ and Cardiac Arrest Study Hamburg (CASH). ${ }^{21}$ A meta-analysis of these randomized, controlled secondary prevention trials showed a $28 \%$ reduction in total mortality compared with drug therapy $(p=0.006) .^{22}$ Furthermore, the results of a subset of patients in the CIDS study who were followed for up to 11 years showed that the benefit of ICD over amiodarone increases with time. ${ }^{23}$

The unequivocal mortality benefit of ICD therapy in these secondary prevention trials formed the basis of class I indica- tion of ICD therapy in patients with aborted SCD and those who survive a hemodynamically compromising VT.

- Primary Prevention: Encouraged by the success of ICDs in the secondary prevention of SCD, the role of ICDs in intercepting the first arrhythmic event has been investigated. In the primary prevention trials, subjects enrolled were those at high risk of experiencing SCD but without history of sustained ventricular arrhythmias. The effect of no treatment and antiarrhythmic or ICD therapy on mortality has been evaluated. The first Multicenter Automatic Defibrillator Implantation Trial (MADIT) randomized subjects with CAD, spontaneous NSVT, LVEF $\leq 35 \%$, and inducible but nonsuppressible VT. ${ }^{24}$ There was $54 \%$ relative mortality reduction at 27 months in the ICD group compared with the conventional therapy group.

The Multicenter Unsustained Tachycardia Trial enrolled a study population similar to that in the MADIT. At 5 years, mortality from all causes among the subjects who received ICDs during the initial hospitalization (24\%) was significantly lower than among the subjects who were treated with drugs $(55 \%)$ and those who received no therapy $(48 \%){ }^{25}$

TABLE 2 Indications for implantable cardioverter defibrillator therapy

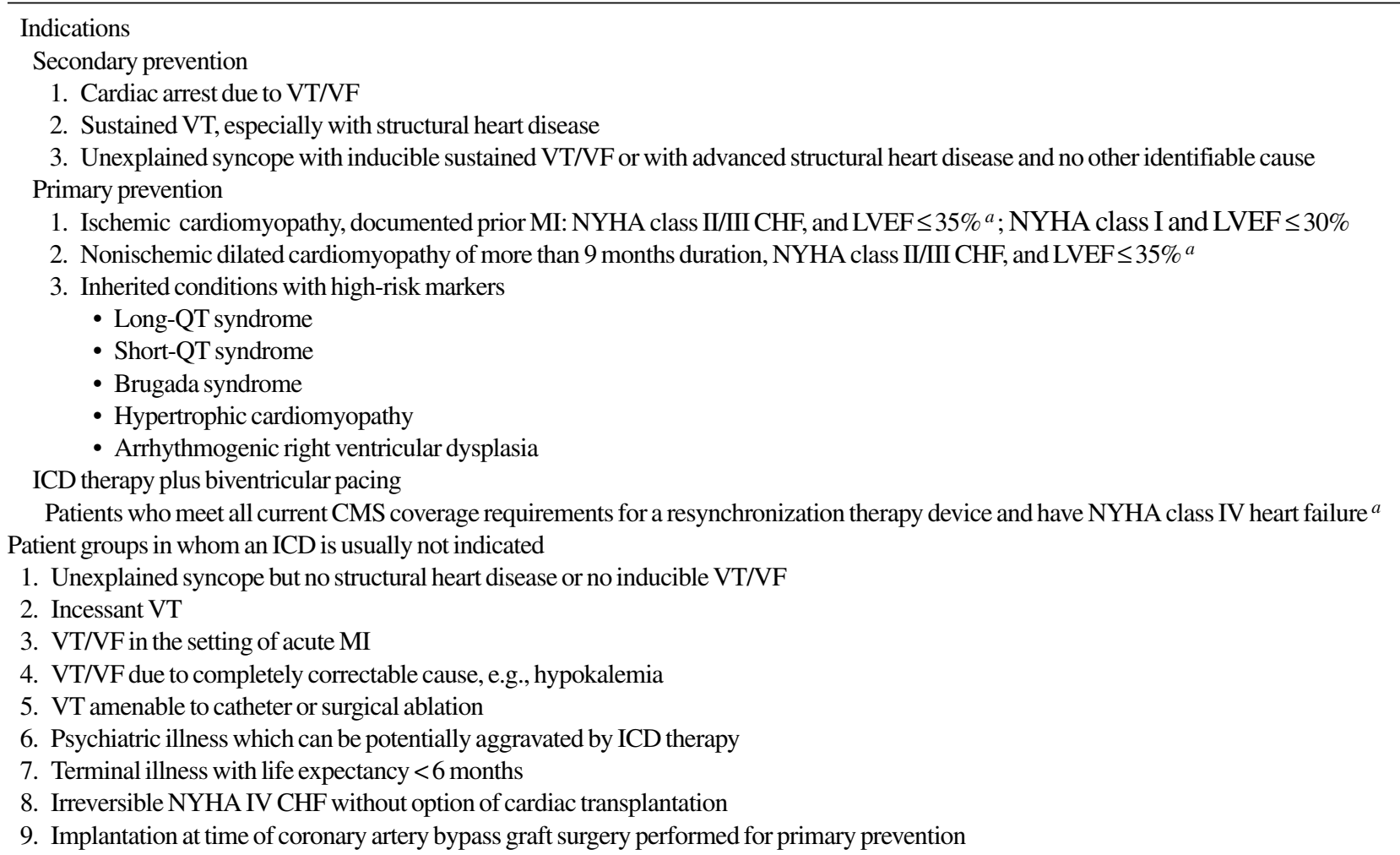

${ }^{a}$ For all groups, (1) patients must not have cardiogenic shock or symptomatic hypotension while in a stable baseline rhythm; (2) had CABG surgery or PTCA within the past 3 months; (3) had an acute MI within the past 40 days; (4) clinical symptoms or findings that would make them a candidate for coronary revascularization; (5) irreversible brain damage from preexisting cerebral disease; or (6) any disease, other than cardiac disease, associated with a likelihood of survival < 1 year. From Centers for Medicare \& Medicaid Services (CMS). ${ }^{31}$

Abbreviations: $\mathrm{LVEF}=$ left ventricular ejection fraction, $\mathrm{CHF}=$ congestive heart failure, $\mathrm{NYHA}=$ New York Heart Association, $\mathrm{CABG}=\mathrm{coro}-$ nary artery bypass graft, PTCA = percutaneous transluminal coronary angioplasty. Other abbreviations as in Table 1 
TABLE 3 Randomized clinical trials of implantable cardioverter defibrillator therapy

\begin{tabular}{|c|c|c|c|c|c|c|c|c|c|}
\hline \multirow[b]{2}{*}{ Trial (Ref. No.) } & \multirow{2}{*}{$\begin{array}{l}\text { No. of } \\
\text { patients }\end{array}$} & \multirow{2}{*}{$\begin{array}{c}\text { Mean age } \\
\text { (years) }\end{array}$} & \multirow{2}{*}{$\begin{array}{c}\text { CAD } \\
(\%)\end{array}$} & \multirow{2}{*}{$\begin{array}{c}\text { LVEF } \\
(\%)\end{array}$} & \multirow{2}{*}{$\begin{array}{l}\text { Follow-up } \\
\text { (months) }\end{array}$} & \multirow[b]{2}{*}{ Control therapy } & \multicolumn{2}{|c|}{ Mortality } & \multirow[b]{2}{*}{$\mathrm{p}$ Value } \\
\hline & & & & & & & Control (\%) & $\operatorname{ICD}(\%)$ & \\
\hline \multicolumn{10}{|c|}{ Primary prevention trials } \\
\hline MADIT (24) & 196 & $63 \pm 9$ & 100 & 26 & 27 & Conventional & 38.6 & 15.8 & 0.009 \\
\hline MADIT II (26) & 1232 & $64 \pm 10$ & 100 & 23 & 20 & Conventional & 19.8 & 14.2 & 0.016 \\
\hline CABG-Patch (42) & 900 & $64 \pm 9$ & 100 & 27 & $32 \pm 16$ & No ICD & 20.9 & 22.6 & 0.64 \\
\hline CAT (34) & 104 & $52 \pm 11$ & 0 & 24 & $66 \pm 26$ & No ICD & 31.4 & 26.0 & 0.55 \\
\hline $\operatorname{MUSTT}(25)^{b}$ & 704 & $66^{a}$ & 100 & $30^{a}$ & $39^{a}$ & Conventional & 32 & 25 & 0.04 \\
\hline DEFINITE (36) & 458 & 58.3 & 0 & 21 & $29 \pm 14$ & Conventional & 14.1 & 7.9 & 0.08 \\
\hline SCD-HeFT (28) & 2521 & $60.1^{a}$ & 52 & $25^{*}$ & $45.5^{a}$ & Conventional, amiodarone & 29 & 22 & 0.007 \\
\hline \multicolumn{10}{|c|}{ Secondary prevention trials } \\
\hline $\operatorname{AVID}(19)$ & 1016 & $65 \pm 11$ & 82 & 35 & $18 \pm 12$ & Amiodarone or sotalol & 24.0 & 15.8 & 0.02 \\
\hline CIDS(20) & 659 & $64 \pm 9$ & 83 & 34 & 35 & Amiodarone & 29.6 & 25.3 & 0.14 \\
\hline CASH(21) & 288 & $58 \pm 11$ & 73 & 45 & $57 \pm 34$ & Amiodarone or metoprolol & 44.4 & 36.4 & 0.08 \\
\hline
\end{tabular}

${ }^{a}$ Median.

${ }^{b}$ The 704 patients with inducible sustained ventricular tachycardia were randomized to no antiarrhythmic treatment $(\mathrm{n}=353)$ or electrophysiologically guided treatment $(n=351)$. The latter were further randomized to antiarrhythmic drugs or ICD.

Plus - minus values are mean \pm SD.

Abbreviations: $\mathrm{LVEF}=$ left ventricular ejection fraction, $\mathrm{CAD}=$ coronary artery disease, $\mathrm{AVID}=$ Antiarrhythmics versus Implantable Defibrillators trial, CIDS $=$ Canadian Implantable Defibrillator Study, CASH = Cardiac Arrest Study Hamburg, MADIT = Multicenter Automatic Defibrillator Implantation Trial (first and second), CABG-Patch = Coronary Artery Bypass Graft Patch, CAT = Cardiomyopathy Trial, MUSTT = Multicenter Unsustained Tachycardia Trial, DEFINITE = Defibrillators in Non-Ischemic Cardiomyopathy Treatment Evaluation, SCD-HeFT $=$ Sudden Cardiac Death in Heart Failure Trial.

However, a significant proportion of patients post MI with LV dysfunction do not have inducible VT and yet experience SCD. This issue was addressed in the second Multicenter Automatic Defibrillator Implantation Trial (MADIT II) in which documentation of spontaneous or inducible arrhythmias was not required. ${ }^{26}$ This trial randomized patients post MI with $\mathrm{LVEF} \leq 30 \%$ to either ICD therapy or conventional medical therapy. ${ }^{26}$ The study was discontinued early after 20 months, when a $30 \%$ reduction in mortality in the ICD group was observed, primarily attributable to a reduction in SCD. ${ }^{26}$ However, in this trial there was no comparison with beta blockers plus amiodarone, a combination that showed a reduction in SCD in the EMIAT and CAMIAT trials. ${ }^{12}$ Indeed, a recent analysis of patients in MADIT II showed that adequate beta blockade decreased VT/VF episodes and improved survival in the ICD subgroup. ${ }^{13}$

Another subgroup analysis of MADIT II demonstrated a progressive increase in the effectiveness of the ICD as QRS duration increased, with ICDs showing little benefit in patients with a QRS $\leq 120 \mathrm{~ms}^{26}$ When QRS duration of $150 \mathrm{~ms}$ was used as a cutoff, a marked reduction in SCD was observed, comparable with MUSTT and MADIT. In this subgroup of patients, survival curves separated at about 1 year and continued to separate thereafter, with an absolute survival benefit of $36 \%$ and a relative risk reduction of $63 \% .^{26,27}$

The Sudden Cardiac Death in Heart Failure (SCD-HeFT) trial randomized 2,521 patients with NYHA class II/III CHF with a mean $\mathrm{LVEF}$ of $25 \%$, approximately half with $\mathrm{CAD}$, to receive either ICD, amiodarone, or conventional treatment. ${ }^{28}$
At a median follow-up of 45.5 months, there was no significant mortality difference between the conventional therapy group (29\%) and the amiodarone group (28\%), but mortality in the ICD group (22\%) was significantly lower. This $7.2 \%$ absolute reduction in mortality with ICDs was observed in both ischemic and nonischemic cardiomyopathy groups, but the benefit was limited to patients in NYHA class II. ${ }^{28}$

Although the risk of SCD is highest in the first 30 days after MI, with risk increasing with increasing LV dysfunction, ${ }^{29}$ the recently concluded Defibrillator IN Acute MI Trial (DINAMIT) trial failed to show survival superiority if ICDs are implanted early after MI. ${ }^{30}$

The Center for Medicare and Medicaid Services, in a memorandum dated January 27, 2005, extended ICD coverage to patients with documented MI, NYHA class II/III CHF, and $\mathrm{LVEF} \leq 35 \%$. $^{31}$

- Non ischemic Dilated Cardiomyopathy: Syncope is reported to be a predictor of SCD in nonischemic dilated cardiomyopathy (NIDCM); NSVT is also a sensitive, but nonspecific marker for SCD risk. Other noninvasive tests have no clear role. Both positive and negative predictive value of EP study for risk stratification is low. Catheter ablation is less effective for arrhythmia control, in part because of the rapidly evolving nature of the underlying substrate. The patient prognosis is most closely linked to severity of LV dysfunction, with progressive $\mathrm{CHF}$ and SCD as competing causes of death.

Angiotensin-converting enzymes inhibitors, beta blockers, and aldosterone receptor blockers reduce sudden and nonsudden mortality. The NIDCM subgroup of Survival Trial of 
Antiarrhythmic Therapy in $\mathrm{CHF}^{32}$ and GESICA ${ }^{33}$ trials reported a mortality benefit with amiodarone; however, the more recent SCD-HeFT study showed no such mortality benefit.

Implantation of ICD is often indicated for symptom control and survival benefit. However, no benefit of ICD on survival was seen in the Cardiomyopathy Trial which enrolled subjects with NIDCM and an LVEF $\leq 30 \% .{ }^{34}$ In the Amiodarone versus ICD Trial, which randomized patients with NIDCM and asymptomatic NSVT, the mortality was similar between amiodarone and ICD groups. ${ }^{35}$

Although these small ICD trials were negative, the more recent larger trials did prove the superiority of ICD. The Defibrillators in Non-Ischemic Cardiomyopathy Treatment Evaluation trial enrolled 458 patients with NIDCM with VPCs or NSVT. ${ }^{36}$ Although the overall mortality was not significantly reduced, the arrhythmic deaths were significantly reduced in the ICD group $(p=0.006)$ compared with standard medical therapy. ${ }^{36}$ As discussed earlier, ICDs in the SCD-HeFT trial, with half the patients with NIDCM, showed significant mortality reduction. ${ }^{28}$

Based on these data, the Center for Medicare and Medicaid Services extended the ICD coverage to patients with NIDCM NYHA class II/III CHF, and LVEF $\leq 35 \%$.

As resynchronization therapy becomes established, there will be an overlap in indications for device therapy. A comparison of medical therapy, pacing, and defibrillation in patients with NYHA class III/IV symptoms despite maximal medical therapy ${ }^{37}$ showed a reduction in the combined endpoint of CHF hospitalization and death in the biventricular pacing and biventricular pacing plus back-up ICD therapy groups (odds ratio 0.82, $\mathrm{p}=0.05$, and $0.81, \mathrm{p}=0.015$, respectively). ${ }^{37}$

\section{Public Access Defibrillation}

Although almost $60 \%$ of SCDs are witnessed by others, about $95 \%$ of victims still die before reaching the hospital. Survival is directly linked to the time interval between the time of cardiac arrest and defibrillation. If no bystander CPR is provided, the victim's chances of survival are reduced by $7-10 \%$ with every minute of delay until defibrillation, such that the survival rate is only $2-5 \%$ if defibrillation is provided more than 12 min after collapse. ${ }^{1,2,38}$

The average time from collapse to beginning CPR and to providing defibrillation varies widely. Communities that are trained in CPR and have strategically placed automated external defibrillators (AEDs) in public buildings and emergency vehicles can have significantly shorter response time. Early CPR and rapid defibrillation combined with early advanced care can produce high long-term survival rates for witnessed cardiac arrest. In some cities in the U.S. with community AED programs, when bystanders provide immediate CPR and the first shock is delivered within 3-5 min, the reported survival rates from sudden cardiac arrest are as high as $48-74 \% .{ }^{4}$ Of importance is the inclusion of AEDs in basic life support management that tremendously improves the out- come for out-of-hospital SCD victims. It has been estimated that if survival rates from SCD were increased from 5 to $20 \%$, approximately 40,000 lives could be saved each year. ${ }^{4}$

Automated external defibrillators are safe for trained lay rescuers to treat SCD because the devices automatically analyze a victim's heart rhythm and allow delivery of electric shock only when necessary. They are easy to use, compact, battery operated, lightweight, portable, and durable. The North American Public Access Defibrillation trial randomized 993 community units to receive volunteer training in CPR or CPR with defibrillation capability. The trial enrolling 19,762 volunteer rescuers showed that with laypersons trained in safe use of AEDs, the number of SCD survivors approximately doubles compared with having laypersons trained in CPR only. ${ }^{39}$ Similar to this experience, a recent study from the U.K. also demonstrated a survival rate of about $23 \%$ with the use of AEDs in out-of-hospital setting. ${ }^{40}$ Furthermore, the Ontario Prehospital Advanced Life Support study showed that addition of prehospital advanced life support provided no additional benefit to a program of early defibrillation in out-of-hospital victims of SCD. ${ }^{41}$

Thus, it may be suggested that like fire extinguishers, AEDs should be made available in public places such as train stations and airports, as well as in malls and shopping centers.

\section{Conclusions}

The incidence of SCD can be reduced by a combination of approaches, which include pharmacologic agents, revascularization therapy, ICD, and resynchronization therapy. Expansion of the use of AEDs will also save lives. Elderly patients should not be denied the benefit of these therapies. Development of newer technologies may shorten the time interval between cardiac arrest and CPR. Finally, since most of the SCDs occur in previously asymptomatic persons, the most important challenge is to identify this subgroup among the general population.

\section{References}

1. Zipes DP, Wellens HJ: Sudden cardiac death. Circulation 1998;98:2334-2351

2. Priori SG, Aliot E, Blomstrom-Lundqvist C, Bossaert L, Breithardt G, et al. Task force on sudden cardiac death of the European Society of Cardiology. Eur Heart J 2001;22:1374-1450

3. Zheng ZJ, Croft JB, Giles WH, Mensah GA: Sudden cardiac death in the United States, 1989 to 1998. Circulation 2001;104:2158-2163

4. American Heart Association website. Sudden deaths from cardiac arrest statistics. Available at: https://www.americanheart.org. Accessed July 21, 2005

5. Spooner PM, Albert C, Benjamin EJ, Boineau R, Elston RC, et al.: Sudden cardiac death, genes and arrhythmogenesis: Consideration of new population and mechanistic approaches from a National Heart, Lung and Blood Institute workshop, part I. Circulation 2001;103:2361-2364

6. Myerburg RJ, Castellanos A: Cardiac arrest and sudden cardiac death. In Heart Disease: A Textbook of Cardiovascular Medicine 7th ed. (Eds. Zipes DP, Libby P, Bonow RO, Braunwald E) pp.865-908. Philadelphia: WB Saunders, 2005

7. Padeletti L, Giaccardi M, Turreni F, Musilli N, Colella A, et al.: Influence of QRS prolongation on the natural history of CHF. Eur Heart J 2004;6(suppl D):D79-D82 
8. Jouven X, Empana JP, Schwartz PJ, Desnos M, Courbon D, et al.: Heart rate profile during exercise as a predictor of sudden death. $N$ Engl J Med 2005;352:1951-1958

9. Armoundas AA, Hohnloser SH, Ikeda T, Cohen RJ: Can microvolt T-wave alternans testing reduce unnecessary defibrillator implantation? Nat Clin Pract Cardiovasc Med 2005;2:522-528

10. Morgan JM: Patients with ventricular arrhythmias: Who should be referred to an electrophysiologist? Heart 2002;88:544-550

11. Echt DS, Liebson PR, Mitchell LB, Peters RW, Obias-Manno D, et al.: for the Cardiac Arrhythmia Suppression Trial Investigators: Mortality and morbidity in patients receiving encainide, flecainide, or placebo: The Cardiac Arrhythmia Suppression Trial. N Engl J Med 1991;324:781-788

12. Beta-Blocker Heart Attack Trial Research Group: A randomized trial of propranolol in patients with acute myocardial infarction, I: Mortality results. JAm MedAssoc 1982;247:1707-1714

13. Brodine WN, Tung RT, Lee JK, Hockstad ES, Moss AJ, et al.: for the MADIT-II Research Group: Effects of beta-blockers on implantable cardioverter defibrillator therapy and survival in the patients with ischemic cardiomyopathy (from the Multicenter Automatic Defibrillator Implantation Trial-II). Am J Cardiol 2005;96:691-695

14. Boutitie F, Boissel JP, Connolly SJ, Camm AJ, Cairns JA, J et al.: for the EMIAT and CAMIAT Investigators: Amiodarone interaction with betablockers: Analysis of the merged EMIAT (European Myocardial Infarct Amiodarone Trial) and CAMIAT (Canadian Amiodarone Myocardial Infarction Trial) databases. Circulation 1999;99:2268-2275

15. Domanski MJ, Exner DV, Borkowf CB, Geller NL, Rosenberg Y, et al.: Effect of angiotensin converting enzyme inhibition on sudden death in patients following acute myocardial infarction: A meta-analysis of randomized clinical trials. J Am Coll Cardiol 1999;33:598-604

16. Lindholm LH, Dahlof B, Edelman JM, Ibsen H, Borch-Johnsen K, et al.: and the LIFE study group: Effect of losartan on sudden cardiac death in people with diabetes: Data from the LIFE study. Lancet 2003;362:619-620

17. Pitt B, Gheorghiade M, Zannad F, Anderson JL, van Veldhuisen DJ, et al.: On behalf of the EPHESUS Investigators: Evaluation of eplerenone in the subgroup of EPHESUS patients with baseline left ventricular ejection fraction $\leq 30 \%$. Eur J Heart Fail 2006;8:295-301

18. Makikallio TH, Barthel P, Schneider R, Bauer A, Tapanainen JM, et al.: Frequency of sudden cardiac death among acute myocardial infarction survivors with optimized medical and revascularization therapy. Am J Cardiol 2006;97:480-484

19. The Antiarrhythmics Versus Implantable Defibrillators (AVID) Investigators: A comparison of antiarrhythmic drug therapy with implantable defibrillators in patients resuscitated from near-fatal ventricular arrhythmias. NEngl J Med 1997;337:1576-1584

20. Connolly SJ, Gent M, Roberts RS, Dorian P, Roy D, et al.: Canadian Implantable Defibrillator Study (CIDS): A randomized trial of the implantable cardioverter defibrillator against amiodarone. Circulation 2000;101:1297-1302

21. Kuck KH, Cappato R, Siebels J, Ruppel R: Randomized comparison of antiarrhythmic drug therapy with implantable defibrillators in patients resuscitated from cardiac arrest: The Cardiac Arrest Study Hamburg (CASH). Circulation 2000;102:748-754

22. Connolly SJ, Hallstrom AP, Cappato R, Schron EB, Kuck KH, et al.: Metaanalysis of the implantable cardioverter defibrillator secondary prevention trials: AVID, CASH and CIDS studies. Eur Heart J 2000;21: 2071-2078

23. Bokhari F, Newman D, Greene M, Korley V, Mangat I, et al.: Long-term comparison of the implantable cardioverter defibrillator versus amiodarone: Eleven-year follow-up of a subset of patients in the Canadian Implantable Defibrillator Study (CIDS). Circulation 2004;110:112-116

24. Moss AJ, Hall WJ, Cannom DS, Daubert JP, Higgins SL, et al.: Improved survival with an implantable defibrillator in patients with coronary disease at high risk for ventricular arrhythmia. N Engl J Med 1996;335:1933-1940

25. Buxton AE, Lee KL, Fisher JD, Josephson ME, Prystowsky EN, et al.: A randomized study of the prevention of sudden death in patients with coronary artery disease. $N$ Engl J Med 1999;341:1882-1890 [Erratum, $N$ Engl J Med 2000;342:1300]
26. Moss AJ, Zareba W, Hall WJ, Klein H, Wilber DJ, et al.: for the Multicenter Automatic Defibrillator Implantation Trial II Investigators: Prophylactic implantation of a defibrillator in patients with myocardial infarction and reduced ejection fraction. N Engl J Med 2002;346:877-883

27. Wilber DJ, Zareba W, Hall WJ, Brown MW, Lin AC, et al:: Time dependence of mortality risk and defibrillator benefit after myocardial infarction. Circulation 2004;109:1082-1084

28. Bardy GH, Lee KL, Mark DB, Poole JE, Packer DL, et al.: for the Sudden Cardiac Death in Heart Failure Trial (SCD-HeFT) Investigators: Amiodarone or an implantable cardioverter-defibrillator for congestive heart failure. N Engl J Med 2005;352:225-237

29. Solomon SD, Zelenkofske S, McMurray JJ, Finn PV, Velazquez E, et al.: for the Valsartan in Acute Myocardial Infarction Trial (VALIANT) Investigators, Valsartan in Acute Myocardial Infarction Trial Investigators: Sudden death in patients with myocardial infarction and left ventricular dysfunction, heart failure, or both. $N$ Engl J Med 2005;352:2581-2588

30. Hohnloser SH, Kuck KH, Dorian P, Roberts RS, Hampton JR, et al.: for the DINAMIT Investigators: Prophylactic use of an implantable cardioverterdefibrillator after acute myocardial infarction. $N$ Engl $J$ Med 2004;351:2481-2488

31. Centers for Medicare \& Medicaid Services Web site. Available at: https://www.cms.hhs.gov. Accessed January 19, 2006

32. Singh SN, Fletcher RD, Fisher SG, Singh BN, Lewis HD, et al.: Amiodarone in patients with congestive heart failure and asymptomatic ventricular arrhythmia. Survival Trial of Antiarrhythmic Therapy in Congestive Heart Failure. N Engl J Med 1995;333:77-82

33. Doval HC, Nul DR, Grancelli HO, Perrone SV, Bortman GR, et al.: Randomized trial of low dose amiodarone in severe congestive heart failure: Grupo de Estudio de la Sobrevida en la Insuficiencia Cardiaca en Argentina (GESICA). Lancet 1994;344:493-498

34. Bansch D, Antz M, Boczor S, Volkmer M, Tebbenjohanns J, et al. Primary prevention of sudden death in idiopathic dilated cardiomyopathy: The Cardiomyopathy Trial. Circulation 2002;105:1453-1458

35. Strickberger SA, Hummel JD, Bartlett TG, Frumin HI, Schuger CD, et al.: for the AMIOVIRT Investigators: Amiodarone versus implantable cardioverter-defibrillator: Randomized trial in patients with nonischemic dilated cardiomyopathy and asymptomatic nonsustained ventricular tachycardia-AMIOVIRT. J Am Coll Cardiol 2003;41:1707-1712

36. Kadish A, Dyer A, Daubert JP, Quigg R, Estes NA, et al.: for the Defibrillators in Non-Ischemic Cardiomyopathy Treatment Evaluation Investigators: Prophylactic defibrillator implantation in patients with nonischemic dilated cardiomyopathy. N Engl J Med 2004;350:2151-2158

37. Bristow MR, Saxon LA, Boehmer J, Krueger S, Kass DA, et al.: for the Comparison of Medical Therapy, Pacing, and Defibrillation in Heart Failure (COMPANION) Investigators: Cardiac resynchronization therapy with or without an implantable defibrillator in advanced chronic heart failure. $N$ Engl J Med 2004;350:2140-2150

38. American Heart Association and International Liaison Committee on Resuscitation: Guidelines 2000 for cardiopulmonary resuscitation and emergency cardiovascular care. Circulation 2000;102(suppl 1):160-176

39. Hallstrom A, Ornato JP, for The Public Access Defibrillation Trial Investigators: Public-access defibrillation and survival after out-of-hospital cardiac arrest. NEngl J Med 2004;351:637-646

40. Davies CS, Colquhoun MC, Boyle R, Chamberlain DA: A national programme for on-site defibrillation by lay people in selected high-risk areas. Heart 2005;91:1299-1302

41. Stiell IG, Wells GA, Field B, Spaite DW, Nesbitt LP, et al.: for the Ontario Prehospital Advanced Life Support Study Group: Advanced cardiac life support in out-of-hospital cardiac arrest. N Engl J Med 2004;351:647-656

42. Bigger JT Jr, for the Coronary Artery Bypass Graft (CABG) Patch Trial Investigators: Prophylactic use of implanted cardiac defibrillators in patients at high risk for ventricular arrhythmias after coronary artery bypass graft surgery. NEngl J Med 1997;337:1569-1575 